\title{
Effects of Dual RAAS Blockade with Candesartan and Perindopril on Functional Renal Tests in Streptozotocin Induced Diabetic Nephropathy
}

\author{
Jasmina Trojacanec ${ }^{1^{\star}}$, Dimce Zafirov ${ }^{1}$, Krume Jakjovski $^{1}$, Kalina Gjorgjievska $^{1}$, Plamen Trojacanec $^{2}$, Nikola Labacevski $^{1}$ \\ ${ }^{1}$ Department of Preclinical and Clinical Pharmacology with Toxicology, Medical Faculty, Skopje, Republic of Macedonia; \\ ${ }^{2}$ Department of Veterinary Surgery, Faculty for Veterinary Medicine, Skopje, Republic of Macedonia
}

\begin{abstract}
Citation: Trojacanec J, Zafirov D, Jakjovski K Gjorgjievska K, Trojacanec P, Labacevski N Effects of Dual RAAS Blockade with Candesartan and Perindopril on Functiona Renal Tests in Streptozotocin Induced Diabetic Nephropathy. Maced J Med Sci. 2013 Sep 15; 6(3):219-226. http://dx.doi.org/10.3889/MJMS.1857 5773.2013.0301.

Key words: Streptozocin; RAAS; candesartan; perindopril; diabetic nephropathy; rats.

"Correspondence: Jasmina Trojacanec. Department of Preclinical and Clinica Pharmacology with Toxicology, Medical Faculty, Ss Cyril and Methodius University, 1000 Skopje Republic of Macedonia. Tel. +389 23111828; +389 $71 \quad 551166$ e-mail: jasmina.trojacanec@yahoo.com
\end{abstract}

Received: 17-Jun-2013; Revised: 20-Jun2013; Accepted: 01-Jul-2013; Online first: 22-Aug-2013

Copyright: (c) 2013 Trojacanec J. This is an open-access article distributed under the terms of the Creative Commons Atribution License, of the Creative Commons Attribution License, and reproduction in any medium, provided the original author and source are credited.

Competing Interests: The authors have declared that no competing interests exist.

\begin{abstract}
Background: Diabetic nephropaty (DN) occurs in approximately $40 \%$ of patients with diabetes mellitus, and is the most common cause of end-stage renal disease. The combination of ACE inhibitors with ARB could lead to a more effective inhibition of rennin angiotensin aldosterone system (RAAS).

Aim: The present study was undertaken to evaluate the effects of dual RAAS blockade with ARB (candesartan) and ACE inhibitor (perindopril) in streptozotocin induced diabetic nephropathy versus ACE-inhibitor or ARB alone.

Materials and Methods: Wistar rats $(n=125)$, were used in this investigation. Diabetes was induced by streptozotocin (STZ) $60 \mathrm{mg} / \mathrm{kg}$. The diabetic rats $(\mathrm{n}=100)$ were randomly assigned to receive vehicle, ARB-Candesartan (5 mg/kg/per d), ACE inhibitor-Perindopril (6 mg/kg/per d), or a combination of low dose Can+Per ( $2.5 \mathrm{mg} / \mathrm{kg} / \mathrm{per} \mathrm{d}$ and $3 \mathrm{mg} / \mathrm{kg} / \mathrm{per} \mathrm{d})$ respectively, from weeks 412.

Results: Treatment with candesartan or perindopril as monotherapy, although significantly, only partially prevented the symptoms and signs of DN. Candesartan and perindopril were equally effective in treatment of DN. Combination therapy was more effective than monotherapy with either drug.

Conclusion: The results from this study demonstrate that combination treatment with both ACE and ARB in low doses may offer synergistic blockade of the RAAS, not obtainable with either drug
\end{abstract} alone.

\section{Introduction}

Diabetic nephropathy (DN) remains the most common cause for end stage renal disease (ESRD) as the burden of diabetes increases worldwide [1- 3]. The mechanisms of DN are not very clear, but the extensive investigation has documented the key role of the rennin angiotensin aldosterone system (RAAS) in the pathogenesis and pathophysiology of DN [4]. Accordingly, blockade of the RAAS is first-line therapy in the treatment of diabetic nephropathy [5].

Blockade of the RAAS has been shown to reduce proteinuria and the rate of decline of glomerular filtration rate (GFR) in proteinuric nephropathies, including diabetic nephropathy.
However not all patients who are treated with angiotensin converting enzyme (ACE) inhibitor or angiotensin receptor blockers (ARB) show a clear antiproteinuric response. An insufficient response to ACE inhibition might be explained by incomplete blockade: At least $40 \%$ of angiotensin II (Angll) is produced via other non-ACE pathways, such as chymase [6]. This incomplete blockade possibly explains the observation thatplasma Angll levels return to normal after chronic ACEl treatment, a phenomenon that is known as ACE escape [7].

Theoretically, treatment with ARB may result in more complete blockade of the unfavorable actions of Angll mediated throughAT1 receptors. Until 
recently, AT1 was considered responsible for most of the actions of Angll: secretion of aldosterone, vasoconstriction, and renal sodium reabsorption. Furthermore, AT1 plays a pivotal role in the pathophysiologic effects of Angll, such as profibrogenic and growth actions. This receptor clearly is the predominant subtype in the adult kidney and is localized in glomeruli and renal tubules. Conversely, AT2 had no or only a marginal role in renal pathology, particularly in adulthood. However, several recent studies demonstrated the presence of the AT2 in adult kidney [8], with a range of effects related to kidney disease: regulation of the chemokine RANTES (Regulated on Activation, Normal T Cell Expressed and Secreted) and the matrix protein osteopontin, mediation of the effects of kinin system on vascular cells, nitric oxide release, and prostaglandin E2 production. Esteban et al. (2004) [9] clearly showed that only combined therapy with AT1 plus AT2 antagonists blocked renal monocyte infiltration, NF-B activation, and upregulation of related proinflammatory genes, showing than the blockade of AT2 is necessary to abolish completely the inflammatory process.

The combination of ACE inhibitors with ARBs could lead to a more effective inhibition of RAAS. Specifically, at the time when the ACE inhibitor dissociates from the ACE active site and angiotensin II concentration increases, the concurrent administration of an ARB will protect AT1 receptors from the effects of angiotensin II. Furthermore, when the ARB dissociates from the AT1, the concurrent administration of an ACE inhibitor will reduce the amount of angiotensin II available to compete with the ARB [10]. Combined RAS blockade may also prevent the ACE escape phenomenon that decreases the effectiveness of ACE inhibitors as ARBs block all angiotensin II action at the AT1 receptor sites. Indeed, evidence suggests that ACE escape occurs in patients with severe congestive heart failure (CHF). Plasma levels of angiotensin II may rise above initial values during long-term ACE inhibition, and the effects of ACE inhibitors on cardiac remodeling and lowering of sympathetic nervous system activity attenuate after 1 year of treatment [11]. Therefore, treatment with both ACE inhibitors and ARB may offer synergistic blockade of the RAAS that is not attainable with either drug alone

The present study was undertaken to evaluate the effects of dual RAAS blockade with ARB (candesartan) and ACE inhibitor (perindopril) on functional renal tests in streptozotocin induced diabetic nephropathy versus ACE inhibitor or ARB alone.

\section{Materials and Methods}

Animal model

Male and female Wistar rats $(n=125), 9-11$ weeks old, with initial body weights of 160-300 g were used in this investigation. Rats were fed with standard food pellets and water ad libitum, housed in cages with a 12-h light/dark cycle and temperature controlled environment (temperature of $20 \pm 2^{\circ} \mathrm{C}$ ). Animal care and treatment were conducted in accordance with institutional guidelines that comply with national and international laws and policies.

\section{Induction of Diabetes}

Diabetes was induced by a single ip injection of STZ (Sigma-Aldrich, Chemie $\mathrm{GmbH}$, Germany) at dosage of $60 \mathrm{mg} / \mathrm{kg}$ dissolved in $0.1 \mathrm{M}$ citrate buffer ( $\mathrm{pH} 4.5)$.

The presence of diabetes was confirmed 72 hours later by the measurement of the tail blood glucose level with a blood glucose monitor (AccuChek, Roche Diagnostic, Germany).

The control group received ip injection of citrate buffer alone (control nondiabetic rats). Blood samples for determination of glucose were obtained by tail bleeding. Only the rats with blood glucose levels $\geq 11 \mathrm{mmol} / \mathrm{L}$, under fasting condition (morning blood samples) were included in the study. In order to develop diabetic nephropathy the animals were left in DM condition without any treatment during the following 4 weeks. The diabetic rats $(n=100)$ were randomly assigned to the four experimental groups (STZ, STZ+CAN, STZ+PER and STZ+CAN+PER). To estimate the symptoms and signs of diabetic nephropathy, the STZ group of rats $(n=25)$ was left without treatment in the following 8 weeks. For assessment of the effects of the AT1 antagonist candesartan (CAN) treatment on rats, in the STZ+CAN group of diabetic rats $(n=25)$, candesartan was administered at dose of $5 \mathrm{mg} / \mathrm{kg} /$ per $\mathrm{d}$ by gavage, from week 4 to week 12. For assessment of the effects of the ACE inhibitor perindopril (PER) treatment on rats, in the STZ+PER group of diabetic rats $(n=25)$, perindopril was administered at dose of 6 $\mathrm{mg} / \mathrm{kg} / \mathrm{per} \mathrm{d}$ by gavage, from week 4 to week 12 . For assessment of the effects of the combination of AT1 antagonist and ARB treatment on rats, in the STZ+CAN+PER group of diabetic rats $(n=25)$, candesartan and perindopril were administered at doses of $2.5 \mathrm{mg} / \mathrm{kg} / \mathrm{per} \mathrm{d}$ and $3 \mathrm{mg} / \mathrm{kg} / \mathrm{per} \mathrm{d}$ respectively, by gavage, from week 4 to week 12 .

The control group (nondiabetic rats) $(n=25)$ received saline in the same volume and at the same time intervals as the groups of animals receiving the tested drugs.

\section{Blood glucose}

The level of blood glucose was determined before the beginning of the investigation, 72 hours after STZ application and after 4, 8 and 12 weeks of the beginning of the study. 


\section{Renal functional tests}

During the study, the renal function in the examined animals was assessed by determination of serum creatinine and blood urea nitrogen (BUN) by autoanalyzer (Cobas Integra 400 Plus; Roche Diagnostics, Germany), as well as determination of the 24-hour urine volume. Urine albumin and protein in 24-hour urine samples was determined by autoanalyzer (Cobas Integra 400 Plus; Roche Diagnostics, Germany). These tests were performed prior to the beginning of the study (Day 0), and at 4, 8 and 12 weeks since the beginning of the study. In order to determine the serum levels of creatinine and BUN, blood was taken by venepuncture from the orbital sinus of the rats under light ether anaesthesia. Blood samples of $400 \mu$ were taken for serum separation $(200 \mu \mathrm{l})$.

Metabolic cages were used for collecting 24hour urine samples for determination of urinary protein and albumin quantity as well as creatinine quantity. Creatinine clearance $(\mathrm{CrCl})$ was calculated from the creatinine concentration in the collected urine sample, urine flow rate, and the plasma concentration of creatinine.

\section{Body weight}

The body weight of the examined animals was measured during the whole study in weekly intervals.

\section{Statistics}

All data were expressed as mean \pm SD. To test more than two groups, Kruskal-Wallis variance analysis was used, followed by Mann-Whitney U-test to determine which groups were significantly different. The $p$-values less than 0.05 were considered as statistically significant.

\section{Results}

\section{Body weight}

Non-diabetic group of rats (Control group) showed a gradual increase in body weight during the study. In STZ-induced diabetic rats, hyperglycemia was found to be associated with significant loss of body weight compared with nondiabetic controls (Figure 1).

At the end of the study, after 12 weeks, the body weight in this group of animals was reduced for $14.9 \%(p<0.05)$ as compared to the basal values. Treatment with candesartan (5 mg/kg/day) or perindopril ( $6 \mathrm{mg} / \mathrm{kg} /$ day) only partially prevented the weight loss among diabetic rats. At the end of the study, the body weight in these groups of animals was increased for $7.5 \%$ and $4.3 \%$ respectively, compared to the basal values. Dual blockade of the RAS with candesartan (2.5 $\mathrm{mg} / \mathrm{kg} / \mathrm{day})$ and perindopril (3 $\mathrm{mg} / \mathrm{kg} /$ day) additional prevented the weight loss, and after 12 weeks the body weight in these groups of animals was increased for $19.4 \%$ compared to the basal value (Figure 1).

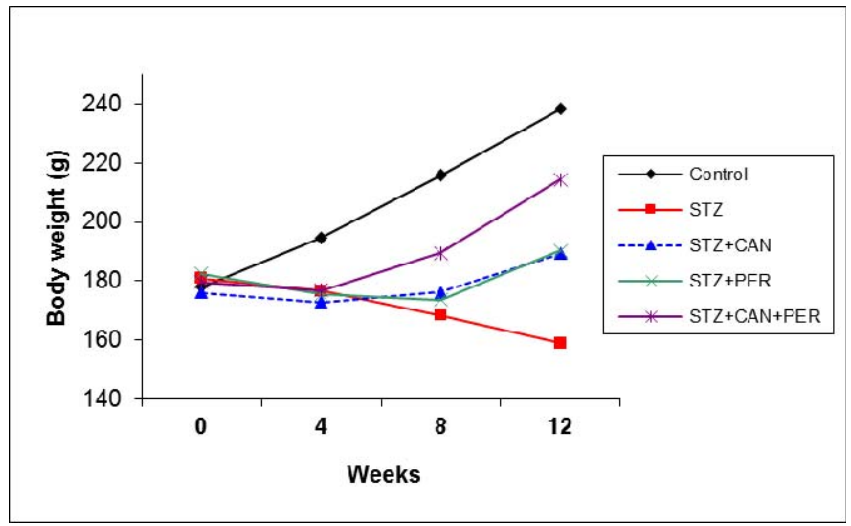

Figure 1: Mean body weight of the investigated groups during the study.

The comparison of the body weight after 12 weeks between the five experimental groups revealed a significant positive effect of combination of candesartan and perindopril (STZ+CAN+PER) on the reduction of body weight $(p<0.05)$ compared with $S T Z$, STZ+CAN and STZ+PER groups (Table 1).

Table 1: Changes in body weight in each experimental group during the study.

\begin{tabular}{|c|c|c|c|c|}
\hline \multicolumn{5}{|l|}{ Body weight (g) } \\
\hline Control & 0-Day & 4-Weeks & 8-Weeks & 12-Weeks \\
\hline & 178.08 & 194.75 & 215.80 & 238.33 \\
\hline SD & 20.69 & 22.43 & 18.10 & 25.88 \\
\hline STZ & & & & \\
\hline $\mathrm{x}$ & 180.78 & $176.61 a$ & $168.33 a$ & $158.92 a$ \\
\hline SD & 20.19 & 23.61 & 24.36 & 18.40 \\
\hline $\mathrm{STZ}+\mathrm{CAN}$ & & & & \\
\hline $\mathrm{x}$ & 176.07 & $172.80 \mathrm{a}$ & $176.15 a$ & 189.20a,b \\
\hline SD & 17.14 & 15.74 & 20.46 & 28.69 \\
\hline STZ+PER & & & & \\
\hline & 182.42 & $175.50 \mathrm{a}$ & $173.55 \mathrm{a}$ & $190.27 a, b$ \\
\hline SD & 25.14 & 29.56 & 27.25 & 21.02 \\
\hline $\mathrm{STZ}+\mathrm{CAN}+\mathrm{PER}$ & & & & \\
\hline & 179.60 & $176.87 a$ & $189.55 a b$ & $214.50 a, b, c$ \\
\hline SD & 15.60 & 20.90 & 19.98 & 22.54 \\
\hline
\end{tabular}

\section{4-hour urine volumen}

After four weeks of administration of streptozotocin, a marked and significant $(p<0.05)$ increase in urine volume was observed in diabetic animals compared with control group of rats. These values in the STZ group were additionally increased after 8 weeks and peaked significantly after 12 weeks. Candesartan and perindopril treatments slightly reduced the urinary volume in diabetic rats. However, the beneficial effects of the candesartan and perindopril monotherapy on 24-hour urine volume were not statistical significant $(p>0.05)$ during the study (Figure 2). 


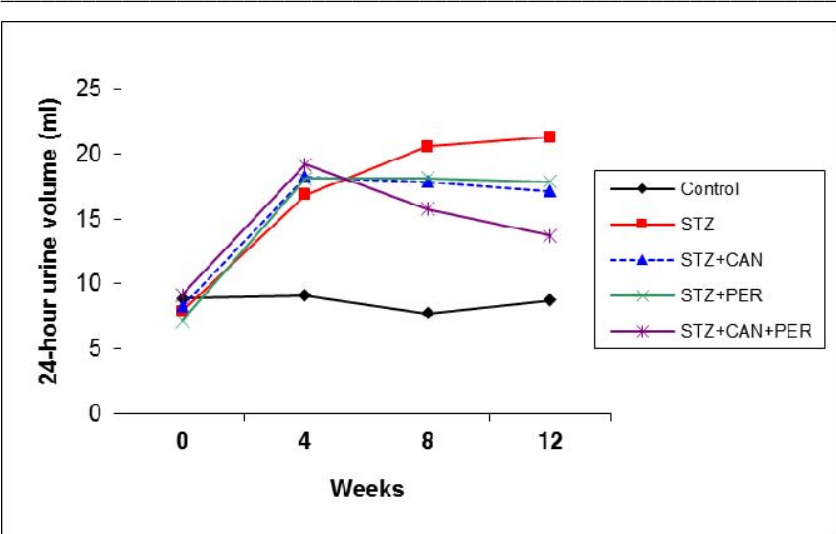

Figure 2: Mean 24-hour urine volume of the investigated groups during the study.

Dual blockade of the RAS at 8 , and 12 weeks, induced statistically significant $(p<0.05)$ reduction on 24-hour urine volume compared with STZ groups of rats, and any type of monotherapy (candesartan or perindopril) (Table 2).

Table 2: Changes in 24-hour urine volume in each experimental group during the study.

\begin{tabular}{|c|c|c|c|c|}
\hline \multicolumn{5}{|c|}{ 24-hours urine volume $(\mathrm{ml})$} \\
\hline Control & 0-Day & 4-Weeks & 8-Weeks & 12-Weeks \\
\hline X & 8.86 & 9.11 & 7.71 & 8.75 \\
\hline SD & 1.35 & 2.15 & 2.29 & 1.83 \\
\hline STZ & & & & \\
\hline $\mathrm{x}$ & 7.86 & $16.89^{\mathrm{a}}$ & $20.57^{\mathrm{a}}$ & $21.29^{a}$ \\
\hline SD & 1.95 & 3.59 & 4.39 & 6.73 \\
\hline STZ+CAN & & & & \\
\hline$x$ & 8.29 & $18.25^{\mathrm{a}}$ & $17.88^{\mathrm{a}}$ & $17.14^{\mathrm{a}}$ \\
\hline SD & 2.21 & 3.20 & 4.19 & 5.81 \\
\hline STZ+PER & & & & \\
\hline $\mathrm{x}$ & 7.14 & $18.10^{\mathrm{a}}$ & $18.13^{\mathrm{a}}$ & $17.86^{\mathrm{a}}$ \\
\hline SD & 1.57 & 4.56 & 4.79 & 3.53 \\
\hline STZ+CAN+PER & & & & \\
\hline & 9.13 & $19.20^{\mathrm{a}}$ & $15.75^{\mathrm{a}, \mathrm{b}}$ & $13.71^{a, b, c}$ \\
\hline SD & 1.73 & 3.94 & 2.96 & 3.04 \\
\hline
\end{tabular}

${ }^{a}<0.05$ vs Control; ${ }^{b}<0.05$ vs STZ; ${ }^{c}<0.05$ vs STZ+PER and STZ+CAN

\section{Serum creatinine and BUN}

For assessment of the renal function in investigated rats, serum creatinine and BUN levels were used as a routine parameters.

At 4 weeks, rats with diabetes exhibited significantly higher values serum creatinine and BUN than control rats and were randomized to receive treatments.

These values in the STZ group were additionally increased after 8 weeks and peaked significantly after 12 weeks. At the end of the study, the serum concentrations of creatinine and BUN in the STZ group were increased about threefold in comparison to the control group and basal values $(p<0.05)$. Monotherapy with candesartan or perindopril, although significantly $(p<0.05)$, only partially reduced the elevated levels of serum creatinine and BUN during the study. Combined administration of candesartan and perindopril further lowered elevated levels of serum creatinine and BUN after 8 and 12 weeks (Figure 3 and 4).

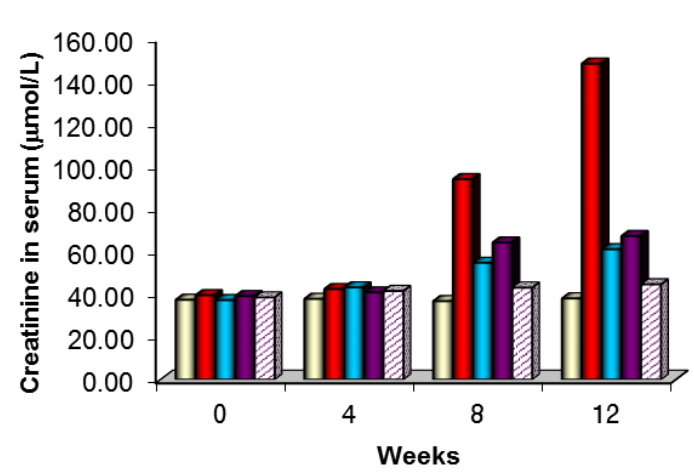

aControl aSTZ aSTZ+CAN aSTZ+PER QSTZ+CAN+PER

Figure 3: Effects of candesartan, perindopril and candesartan + perindopril treatments on serum creatinine levels during the study.

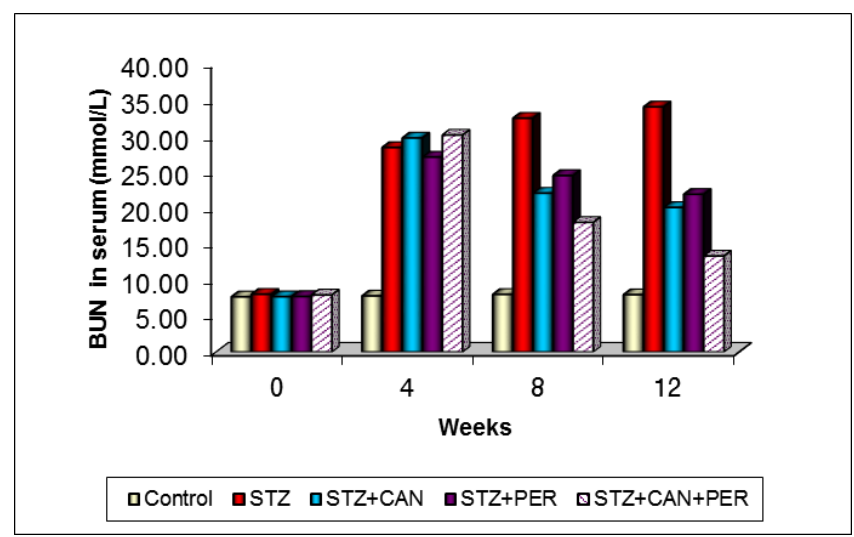

Figure 4: Effects of candesartan, perindopril and candesartan + perindopril treatments on BUN levels during the study.

Comparative statistical analysis of the serum creatinine and BUN levels of the STZ+CAN and STZ+PER groups has shown similar effects without significant differences $(p>0.05)$. However, during the study (at weeks 8 and 12), mean serum creatinine and BUN levels of rats given a combination of candesartan and perindopril were significantly lower $(p<0.05)$ than those of diabetic rats treated with candesartan or perindopril monotherapy (Table 3).

Table 3: Effects of candesartan, perindopril and candesartan + perindopril treatments on serum creatinine and BUN in rats with STZ induced diabetic nephropathy.

\begin{tabular}{|c|c|c|c|c|c|c|c|c|}
\hline & \multicolumn{4}{|c|}{ Serum creatinine $(\mu \mathrm{mol} / \mathrm{L})$} & \multicolumn{4}{|c|}{$B U N(m m o / / L)$} \\
\hline & \multicolumn{4}{|c|}{$\begin{array}{l}\text { Weeks of the treatment } \\
4\end{array}$} & \multicolumn{4}{|c|}{ Weeks of the treatment } \\
\hline \multicolumn{9}{|c|}{ Control } \\
\hline $\mathrm{x}$ & 37.44 & 37.89 & 36.81 & 38.11 & 7.67 & 7.79 & 8.01 & 7.96 \\
\hline SD & 3.18 & 3.78 & 3.53 & 3.37 & 1.90 & 1.75 & 1.45 & 1.85 \\
\hline \multicolumn{9}{|c|}{ STZ } \\
\hline $\mathrm{x}$ & 39.58 & 42.49 & $94.09^{\mathrm{a}}$ & $148.3^{\mathrm{a}}$ & 8.03 & $28.41^{\mathrm{a}}$ & $32.48^{\mathrm{a}}$ & $34.05^{\mathrm{a}}$ \\
\hline$\widehat{S D}$ & 5.43 & 7.37 & 41.63 & 67.91 & 1.79 & 12.48 & 16.45 & 20.63 \\
\hline \multicolumn{9}{|c|}{$\mathrm{STZ}+\mathrm{CAN}$} \\
\hline$x$ & 37.31 & 43.27 & $54.82^{\mathrm{a}, \mathrm{b}}$ & $61.18^{a, b}$ & 7.69 & $29.73^{\mathrm{a}}$ & $22.07^{\mathrm{a}, \mathrm{b}}$ & $20.08^{\mathrm{a}, \mathrm{b}}$ \\
\hline$\widehat{S D}$ & 4.27 & 9.12 & 18.95 & 19.18 & 2.05 & 10.92 & 9.53 & 8.30 \\
\hline \multicolumn{9}{|c|}{ STZ + PER } \\
\hline & 39.18 & 40.93 & $64.34^{\mathrm{a}, \mathrm{b}}$ & $67.37^{\mathrm{a}, \mathrm{b}}$ & 7.72 & $27.08^{\mathrm{a}}$ & $24.52^{\mathrm{a}, \mathrm{b}}$ & $21.91^{\mathrm{a}, \mathrm{b}}$ \\
\hline$\widehat{S D}$ & 4.08 & 7.80 & 26.00 & 19.41 & 2.15 & 10.88 & 11.73 & 9.76 \\
\hline \multicolumn{9}{|c|}{$\mathrm{STZ}+\mathrm{CAN}+\mathrm{PER}$} \\
\hline $\mathrm{x}$ & & & $43.18^{\mathrm{a}, \mathrm{b}, \mathrm{c}}$ & $44.72^{\mathrm{a}, \mathrm{b}, \mathrm{c}}$ & 7.93 & $30.14^{\mathrm{a}}$ & $18.01^{\mathrm{a}, \mathrm{b}, \mathrm{c}}$ & $13.34^{\mathrm{a}, \mathrm{b}, \mathrm{c}}$ \\
\hline$\hat{\mathrm{SD}}$ & 2.64 & $\begin{array}{l}4.00 \\
6.92\end{array}$ & 6.25 & 6.34 & 2.00 & 10.93 & 10.33 & 5.04 \\
\hline
\end{tabular}




\section{Urine albumin and protein}

Significant $(p<0.05)$ increase of the urine albumin and protein values were recorded 4 weeks after the administration of STZ. These values in the STZ group were additionally increased after 8 weeks and peaked significantly after 12 weeks.

Albuminuria and proteinuria were significantly reduced by all three types of interruption of the RAS compared with STZ group of rats. Candesartan and perindopril were equally effective. Dual blockade of the RAS induced an additional reduction in albuminuria and proteinuria compared with any type of monotherapy (Figure 5 and 6).

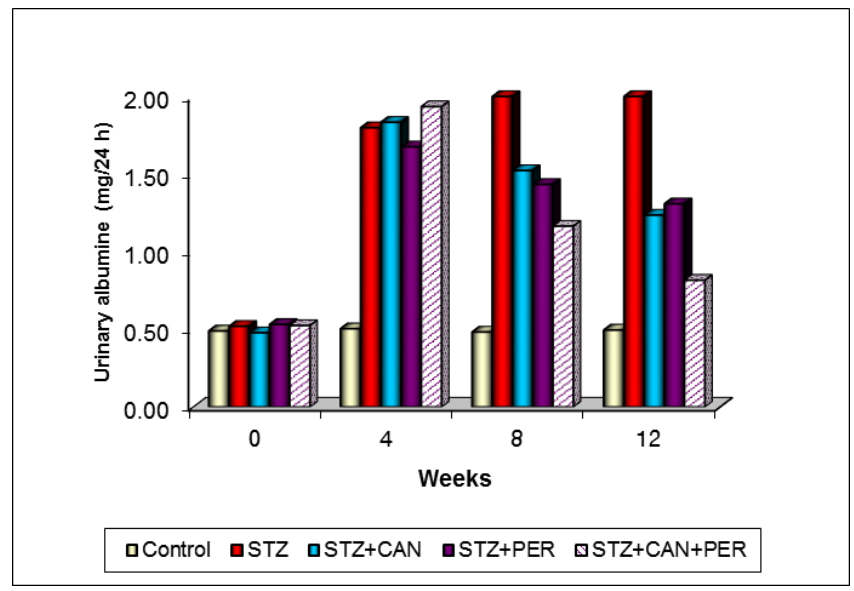

Figure 5: Effects of candesartan, perindopril and candesartan + perindopril treatments on urinary albumin levels.

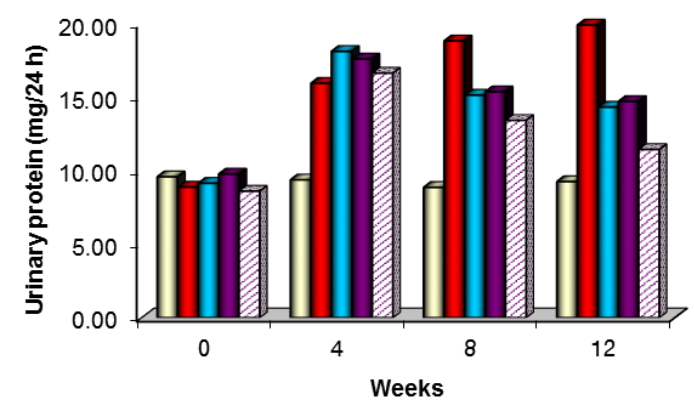

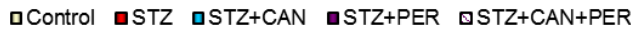

Figure 6: Effects of candesartan, perindopril and candesartan + perindopril treatments on urinary protein levels.

The comparison of the urine albumin and protein excretion after 8 and 12 weeks between the all three types of interruption of the RAS revealed a statistically significant positive effect of dual blockade of the RAS with candesartan and perindopril on the reduction of albuminuria and proteinuria versus monotherapy with the some drugs $(p<0.05)$ (Table 4$)$.

\section{Creatinine clearance}

Creatinine clearance was used as specific parameter to assess glomerular filtration rate (GFR).
Table 4: Effects of candesartan, perindopril and candesartan + perindopril treatments on urinary albumin and protein excretion in rats with STZ induced diabetic nephropathy.

\begin{tabular}{|c|c|c|c|c|c|c|c|c|}
\hline & \multicolumn{4}{|c|}{ Urine albumine (mg/24h) } & \multicolumn{4}{|c|}{ Urine protein (mg/24h) } \\
\hline & & Weeks & he treatme & & & Weeks & the treatm & \\
\hline & 0 & 4 & 8 & 12 & 0 & 4 & 8 & 12 \\
\hline \multicolumn{9}{|c|}{ Control } \\
\hline & 0.490 & 0.504 & 0.483 & 0.496 & 9.60 & 9.39 & 8.88 & 9.27 \\
\hline SD & 0.118 & 0.120 & 0.109 & 0.116 & 1.62 & 1.81 & 1.85 & 1.20 \\
\hline \multicolumn{9}{|c|}{ STZ } \\
\hline $\mathrm{x}$ & 0.520 & $1.799^{\mathrm{a}}$ & $2.523^{\mathrm{a}}$ & $3.316^{\mathrm{a}}$ & 8.90 & $15.97^{\mathrm{a}}$ & $18.85^{\mathrm{a}}$ & $19.93^{\mathrm{a}}$ \\
\hline SD & 0.158 & 0.775 & 0.824 & 0.822 & 1.72 & 3.65 & 4.27 & 4.40 \\
\hline \multicolumn{9}{|c|}{ STZ+CAN } \\
\hline $\mathrm{x}$ & 0.478 & $1.834^{\mathrm{a}}$ & $1.523^{\mathrm{a}, \mathrm{b}}$ & $1.236^{\mathrm{a}, \mathrm{b}}$ & 9.16 & $18.14^{\mathrm{a}}$ & $15.16^{\mathrm{a}, \mathrm{b}}$ & $14.34^{\mathrm{a}, \mathrm{b}}$ \\
\hline SD & 0.127 & 0.796 & 0.556 & 0.505 & 1.87 & 4.04 & 4.18 & 2.98 \\
\hline \multicolumn{9}{|c|}{ STZ+PER } \\
\hline $\mathrm{x}$ & 0.532 & $1.676^{\mathrm{a}}$ & $1.434^{\mathrm{a} . \mathrm{b}}$ & $1.309^{\mathrm{a}, \mathrm{b}}$ & 9.79 & $17.62^{\mathrm{a}}$ & $15.39^{a, b}$ & $14.73^{\mathrm{a}, \mathrm{b}}$ \\
\hline SD & 0.140 & 0.596 & 0.591 & 0.535 & 1.67 & 4.38 & 3.22 & 3.09 \\
\hline \multicolumn{9}{|c|}{ STZ+CAN+PER } \\
\hline $\mathrm{x}$ & 0.525 & $1.935^{\mathrm{a}}$ & $1.165^{\mathrm{a}, \mathrm{b}}$ & $0.817^{\mathrm{a}, \mathrm{b}, \mathrm{c}}$ & 8.62 & $16.66^{\mathrm{a}}$ & $13.44^{\mathrm{a}, \mathrm{b}}$ & $11.46^{\mathrm{a}, \mathrm{b}, \mathrm{c}}$ \\
\hline SD & 0.110 & 0.758 & 0.423 & 0.310 & 2.22 & 3.57 & 2.84 & 1.60 \\
\hline
\end{tabular}

In the early weeks of diabetes (after 4 weeks of administration of STZ), there was a significant $(p<0.05)$ increase in creatinin clearance that gradually decreased in later weeks. After 8 weeks, the creatinine clearance values in the STZ group were decreased about two fold in comparison to the control group and basal values $(p<0.05)$. At the end of the study, after 12 weeks, there was an additional decrease of the creatinine clearance values (for $62 \%$ compared to basal values) (Figure 7 and 8).

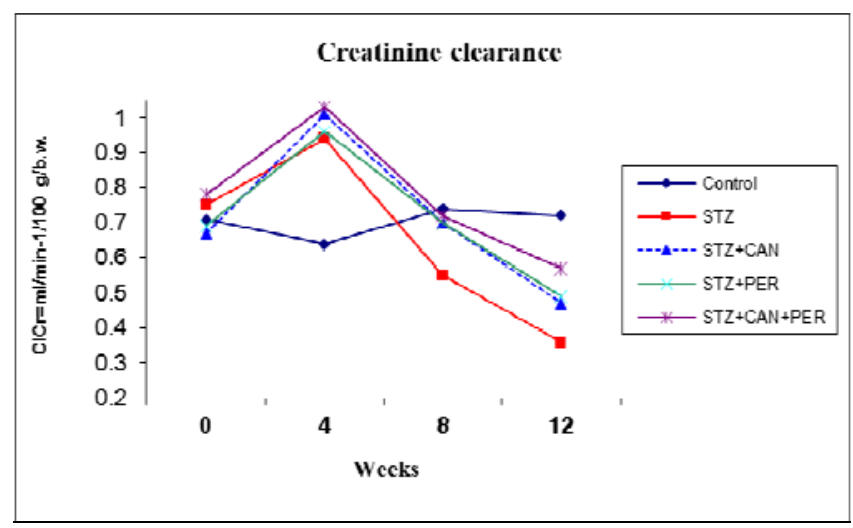

Figure 7: Effects of candesartan, perindopril and candesartan + perindopril treatments on creatinine clearance during the study.

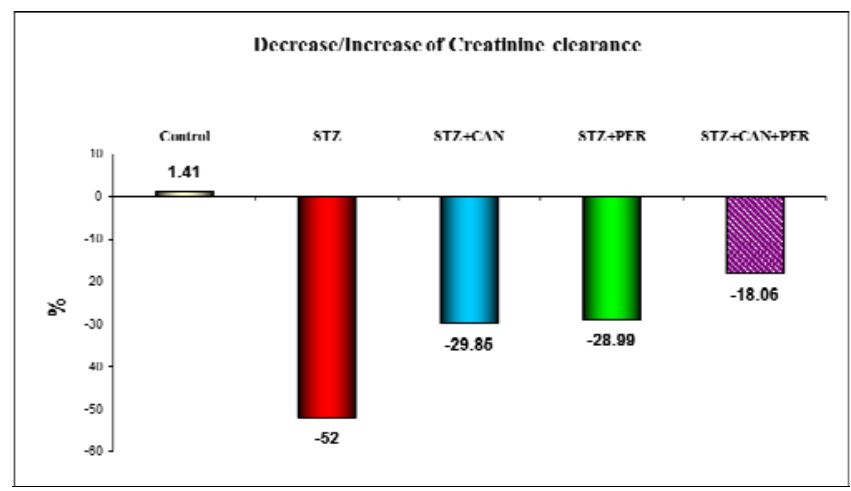

Figure 8: Decrease/Increase of creatinine clearance (\%) at the end of the study.

Treatment with candesartan or perindopril (as a monotherapy), partially prevented the decrease of creatinine clearance among diabetic rats. At the end 
of the study, the creatinin clearance in these groups of animals was decreased for $29.85 \%$ and $28.99 \%$ respectively, compared to the basal values. Dual blockade of the RAS additional prevented the decrease of creatinin clearance, and after 12 weeks the mean value of creatinin clearance in these groups of animals was decreased only for $18.6 \%$ compared to the basal values (Figure 7 and 8).

The comparison of the levels of creatinine clearance during the study (at 4,8 and 12 weeks) between the five experimental groups, revealed a significant positive effect of combination of candesartan and perindopril (STZ+CAN+PER) on the reduction of creatinine clearance $(p<0.05)$ compared with STZ, STZ+CAN and STZ+PER groups (Table 5).

Table 5: Effects of candesartan, perindopril and candesartan + perindopril treatments on creatinine clearance in rats with STZ induced diabetic nephropathy.

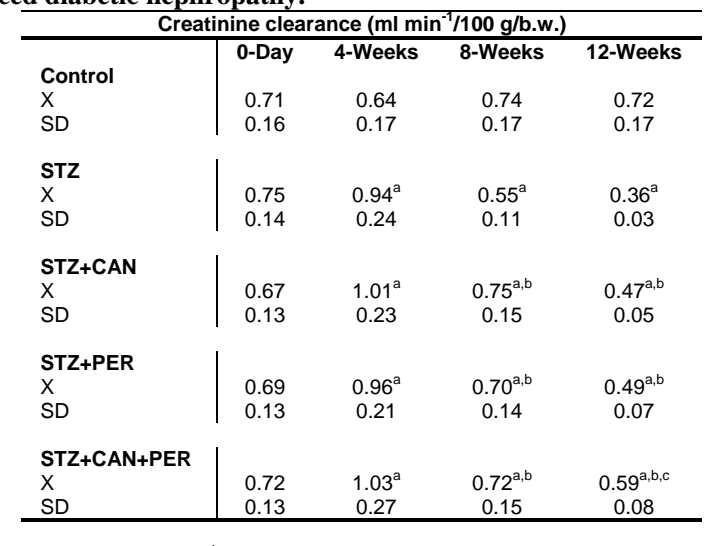

${ }^{a}<0.05$ vs Control; ${ }^{\mathrm{b}}<0.05$ vs STZ; ${ }^{\mathrm{c}}<0.05$ vs STZ+PER and STZ+CAN

\section{Discussion}

Diabetic nephropathy, classically defined by the presence of proteinuria (macroalbuminuria, or "severely increased albuminuria"), is a common problem that is most likely to occur in patients who have worse glycemic control, hypertension, glomerular hyperfiltration or a genetic predisposition [12]. The lifetime risk of nephropathy is roughly equivalent in type 1 and type 2 diabetes [13].

The earliest clinical manifestation of renal involvement in diabetes is an increase in albumin excretion (microalbuminuria, or "moderately increased albuminuria"), a stage at which renal histology may be relatively normal or may reveal glomerulosclerosis [14-17].

For the time being there is no specific treatment for diabetic nephropathy. The best way for the treatment is prevention, in a form of early detection and treatment of microalbuminuria.

The rennin angiotensin aldosteron system (RAAS) is a key player in the progression of diabetic renal disease. Agents blocking the renin angiotensin system, angiotensin converting enzyme (ACE) inhibitors and angiotensin receptor blockers (ARB), are preferred for preventing albuminuria and delaying progression of DN [18].

The primary effect of ACE inhibitors is mediated through reduced generation of angiotensin II, but additional effects, perhaps mediated through bradykinin accumulation, may also contribute to the beneficial effect. ACE inhibitors are currently first-line therapy in type 1 diabetic patients with diabetic nephropathy according to the Captopril Collaborative Study [19] but the effect of ARBs has not been investigated thoroughly.

Despite maximal recommended doses of ACE inhibitors, several patients with diabetic nephropathy do not reach blood pressure target, have persistent albuminuria and rapid progression of renal disease. Insufficient response during sustained therapy may be partly related to under-dosing or the ACE-escape phenomenon, generation of angiotensin II through alternate enzyme pathways such as chymase [20] or individual factors.

Blockade of the RAAS at AT1 receptor level by ARB treatment should overcome these drawbacks, but a potential benefit from bradykinin accumulation during $A C E$ inhibitor treatment will then be missed. Furthermore, increased plasma concentrations of angiotensin II during ARB treatment [21, 22] could be unfavorable if AT2 receptor stimulation confers adverse renal effects as suggested by Cao et al [23, 24]. Concomitant ACE inhibitor treatment reduces angiotensin II levels [22], thus, dual blockade of the RAAS by ACE inhibition and ARBs may offer additional renoprotective effect compared to monotherapy with either agent alone.

In our study, the single i.p. administration of STZ have caused diabetes with clearly symptoms and signs of diabetic nephropathy, including poor general condition, body weight loss, as well as abnormalities of serum and urinary renal function tests. In diabetic rats, significant increased values of serum creatinine and BUN, accompanied by increased diuresis, proteinuria, albuminuria and decreased clearance of creatinine (as a measure of glomerular filtration rate) of the experimental animals have been manifested 4 weeks after, and even more distinctly 8 and 12 weeks after administering STZ.

Treatment with candesartan ( $5 \mathrm{mg} / \mathrm{kg} /$ day) or perindopril (6 $\mathrm{mg} / \mathrm{kg} /$ day) as monotherapy, although significantly, only partially prevented the symptoms and signs of DN among diabetic rats. Candesartan and perindopril were equally effective in treatment of DN in diabetic rats.

Combination therapy with candesartan and perindopril was more effective than monotherapy with either drug in the treatment of diabetic nephropathy.

Dual RAAS blockade with candesartan and perindopril significantly decreased all symptoms and signs of DN. Diabetic rats treated with candesartan 
and perindopril showed a significant reduction of the values of BUN and serum creatinine, albuminuria, proteinuria, glomerular filtration rate and diuresis compared to monotherapy.

The results obtained from this study clearly demonstrate that combination treatment with low doses of both drugs is more effective than higher doses of each compound on all tested parameters.

The rationale for dual blockade of the RAS system is based on the different mechanisms of action of the two drug classes. In addition to decreased Angll formation ACE-I decrease the degradation of bradykinin, a powerful vasodilator [25]. However, an insufficient response to ACE-I might be explained by incomplete blockade of the ACE enzyme or by the generation of Angll by ACE-independent pathways such as chymase [26]. The incomplete blockade possibly explains the observation that plasma Angll levels return to normal after chronic ACE-I treatment, a phenomenon called ACE-escape [27]. Treatment with Angll receptor blockers may result in more complete blockade of the unfavorable actions of Angll mediated through the Angll type 1 receptor. However, new data from animal studies indicate that some of the deleterious effects of Angll on glomerular cell migration, tubular cell proliferation, and development of urinary protein excretion may be mediated through the Angll type 2 receptor [28-30]. Therefore, treatment with both ACE and ARB may offer synergistic blockade of the RAAS, not obtainable with either drug alone.

A recent study of combined treatment with ACE inhibition and ARB in healthy rats demonstrated that renal angiotensin II levels were lowered by monotherapy with either agent [31] in accordance with previous experimental studies of ARBs [32]. Dual blockade of the RAAS caused a further reduction of kidney angiotensin II levels, whereas separate doseescalation studies of both agents were unable to demonstrate similar degree of suppression of kidney angiotensin II levels. According to these experimental data, combined treatment with ACE inhibition and ARB may induce a supplementary effect on the intrarenal RAAS, unavailable by monotherapy with either agent.

\section{Referenes}

1. Choudhury D, Tuncel M, Levi M. Diabetic nephropathy-a multifaceted target of new therapies. Discov Med. 2010; 10(54):406-15

2. Kaul K, Hodgkinson A, Tarr JM, Kohner EM, Chibber R. Is inflammation a common retinal-renal-nerve pathogenic link in diabetes? Curr Diabetes Rev. 2010; 6(5):294-303.

3. Wu AY, Kong NC, De Leon FA, Pan CY, Tai TY, Yeung VT, Yoo SJ, Rouillon A, Weir MR. An alarmingly high prevalence of diabetic nephropathy in Asian type 2 diabetic patients: the MicroAlbuminuria Prevalence (MAP) Study. Diabetologia. 2005; 48(1):17-26

4. di Mario U, Morano S, Cancelli A, Bacci S, Frontoni S,
Pietravalle $P$ et al. New parameters to monitor the progression of diabetic nephropathy. Am J Kidney Dis. 1989;13(1):45-48.

5. Kverneland A, Feldt-Rasmussen B, Vidal P, Welinder B, BentHansen $L$, Soegaard $U$ et al. Evidence of changes in renal charge selectivity in patients with type 1 (insulin-dependent) diabetes mellitus. Diabetologia. 1986; 29(9):634-639.

6. Hollenberg NK, Fisher ND, Price DA. Pathways for angiotensin II generation in intact human tissue. Evidence from comparative pharmacological interruption of the renin system. Hypertension. 2000; 32:387-392.

7. Nussberger J, Brunner DB, Waeber B, Brunner HR. Plasma angiotensins under sustained converting enzyme inhibition with enalapril in normal humans. J Hypertens. 1985; Suppl 3: S269-S270.

8. Cao Z, Kelly DJ, Cox AJ, Casley D, Forbes J, Martinello P Dean R, Gilbert R, Cooper M. The angiotensin type 2 receptor is expressed in adult rat kidney and promotes cellular proliferation and apoptosis. Kidney Int. 2000; 58:2437 -2451.

9. Esteban V, Lorenzo O, Ruiperez M, Suzuki Y, Mezzano S, Blanco J, Kretzles M, Sugaya T, Egido J, Ruiz Ortega M. Angiotensin II, via AT1 and AT2 receptors and NF-kappaB pathway, regulates the inflammatory response in unilateral ureteral obstruction. J Am Soc Nephrol. 2004; 15:1514-1529.

10. Azizi M, Ménard J. Combined blockade of the reninangiotensin system with angiotensin-converting enzyme inhibitors and angiotensin II type 1 receptor antagonists. Circulation. 2004; 109:2492-2499.

11. Ennezat PV, Berlowitz $M$, Sonnenblick EH, Le Jemtel TH. Therapeutic implications of escape from angiontensinconverting enzyme inhibition in patients with chronic heart failure. Curr Cardiol Rep. 2000; 2:258-262,

12. Earle, K, Viberti, GC. Familial, hemodynamic and metabolic factors in the predisposition to diabetic kidney disease. Kidney Int. 1994; 45: 434.

13. Ritz E, Orth SR. Nephropathy in patients with type 2 diabetes mellitus. N Engl J Med. 1999; 341:1127.

14. Chavers BM, Bilous RW, Ellis EN, et al. Glomerular lesions and urinary albumin excretion in type I diabetes without overt proteinuria. N Engl J Med. 1989; 320:966.

15. Cooper ME. Pathogenesis, prevention, and treatment of diabetic nephropathy. Lancet. 1998; 352:213.

16. Ismail N, Becker B, Strzelczyk P, Ritz E. Renal disease and hypertension in non-insulin-dependent diabetes mellitus. Kidney Int. 1999; 55:1.

17. Gross JL, de Azevedo MJ, Silveiro SP, et al. Diabetic nephropathy: diagnosis, prevention, and treatment. Diabetes Care. 2005; 28:164.

18. Lasaridis AN, Sarefidis PA. Diabetic nephropathy and antihypertensive treatment: what are the lessons from clinical trials? Am J Hypertens. 2003; 16:689-97.

19. Christensen EI, Carone FA, Rennke HG. Effect of molecular charge on endocytic uptake of ferritin in renal proximal tubule cells. Lab Invest. 1981; 44(4):351-358.

20. Hollenberg NK, Fisher NDL, Price DA. Pathways for angiotensin II generation in intact human tissue. Evidence from comparative pharmacological interruption of the renin system. Hypertension. 1998; 32:387-392.

21. Brenner BM, Cooper ME, de Zeeuw D, Keane WF, Mitch WE, Parving $\mathrm{HH}$ et al. Effects of losartan on renal and cardiovascular outcomes in patients with type 2 diabetes and nephropathy. N Engl J Med. 2001; 345(12):861-869.

22. Jacobsen $\mathrm{P}$, Andersen $\mathrm{S}$, Jensen BR, Parving $\mathrm{HH}$. Additive effect of ACE inhibition and Angiotensin II receptor blockade in type 1 diabetic patients with diabetic nephropathy. J Am Soc Nephrol. 2003; 14(4):992-9. 
23. Bakris GL, Copley JB, Vicknair N, Sadler R, Leurgans S Calcium channel blockers versus other antihypertensive therapies on progression of NIDDM associated nephropathy. Kidney Int. 1996; 50:1641-1650.

24. Nielsen FS, Rossing $P$, Gall M-A, Skøtt $P$, Smidt UM, Parving $\mathrm{HH}$. Long-term effect of lisinopril and atenolol on kidney function in hypertensive non-insulin-dependent diabetic subjects with diabetic nephropathy. Diabetes. 1997; 46:11821188.

25. Vanhoutte PM: Endothelium and control of vascular function. State of the Art lecture. Hypertension. 1989; 13:658-667.

26. Hollenberg NK, Fisher ND, Price DA: Pathways for angiotensin II generation in intact human tissue. Evidence from comparative pharmacological interruption of the renin system. Hypertension. 1998; 32:387-392.

27. Nussberger J, Brunner DB, Waeber B, Brunner HR. Plasma angiotensins under sustained converting enzyme inhibition with enalapril in normal humans. J Hypertension. 1985; Suppl 3: S269-S270.

28. Wolf G, Ziyadeh FN, Thaiss F, Tomaszewski J, Caron RJ, Wenzel U, Zahner G, Helmchen U, Stahl RA. Angiotensin II stimulates expression of the chemokine RANTES in rat glomerular endothelial cells. Role of the angiotensin type 2 receptor. J Clin Invest. 1997; 100:1047-1058.

29. Cao Z, Kelly DJ, Cox A, Casley D, Forbes JM, Martinello P, Dean R, Gilbert RE, Cooper ME. Angiotensin type 2 receptor is expressed in the adult rat kidney and promotes cellular proliferation and apoptosis. Kidney Int. 2000; 58:2437-2451.

30. Cao Z, Bonnet F, Candido R, Nesteroff SP, Burns WC, Kawachi H, Shimizu F, Carey RM, De Gasparo M, Cooper ME. Angiotensin type 2 receptor antagonism confers renal protection in a rat model of progressive renal injury. J Am Soc Nephrol. 2002; 13: 1773-1787.

31. Komine N, Khang S, Wead LM, Blantz RC, Gabbai FB. Effect of combining an ACE inhibitor and an angiotensin II receptor blocker on plasma and kidney tissue angiotensin II levels. Am J Kidney Dis. 2002; 39(1):159-164.

32. Navar LG, Harrison-Bernard LM, Imig JD, Wang CT, Cervenka $\mathrm{L}$, Mitchell KD. Intrarenal angiotensin II generation and renal effects of AT1 receptor blockade. J Am Soc Nephrol. 1999;10(Suppl. 12):S266-S272. 